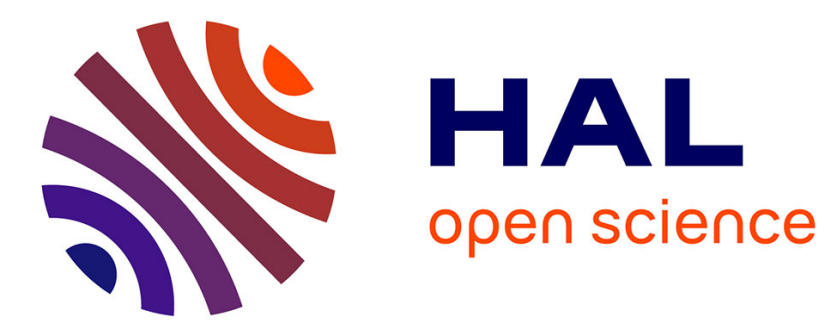

\title{
Implementing Wideband Monopole/Dipole Antennas on Paper Substrates
}

\author{
Christian Person, Duc Nguyen, J Ph Coupez, Ph Minard, D. Lohine Tong, \\ Patrick Borel, D Izoard
}

\section{To cite this version:}

Christian Person, Duc Nguyen, J Ph Coupez, Ph Minard, D. Lohine Tong, et al.. Implementing Wideband Monopole/Dipole Antennas on Paper Substrates. 2018 15th European Eurepean Conference (EuRAD), Sep 2018, Madrid, Spain. 10.23919/EuRAD.2018.8546518 . hal-02114426

\section{HAL Id: hal-02114426 \\ https://hal.science/hal-02114426}

Submitted on 29 Apr 2019

HAL is a multi-disciplinary open access archive for the deposit and dissemination of scientific research documents, whether they are published or not. The documents may come from teaching and research institutions in France or abroad, or from public or private research centers.
L'archive ouverte pluridisciplinaire HAL, est destinée au dépôt et à la diffusion de documents scientifiques de niveau recherche, publiés ou non, émanant des établissements d'enseignement et de recherche français ou étrangers, des laboratoires publics ou privés. 


\title{
Implementing Wideband Monopole/Dipole Antennas on Paper Substrates
}

\author{
Ch. Person ${ }^{\#}$, Duc NGuyen ${ }^{\#}$ J.Ph. Coupez ${ }^{\#}$, Ph. Minard*, D. Lo Hine Tong ${ }^{*}$, P. Borel ${ }^{\S}$, D. Izoard ${ }^{\S}$ \\ ${ }^{*}$ LabSTICC, IMT Atlantique, France \\ ${ }^{*}$ Technicolor Connected Home, France \\ $\S_{\text {Centre Technique du Papier, France }}$ \\ \#\{christian.person, hong.nguyen, jp.coupez\}@imt-atlantique.fr, \\ *\{philippe.minard,dominique.lohinetong\}@technicolor.com, ${ }^{\S}\{$ pascal.borel, damien.izoard\}@webctp.com
}

\begin{abstract}
Advanced internet and multimedia set-top boxes are today massively based on $4 * 4$ MIMO systems, with multisub-bands standards (Wifi bands, LTE, Bluetooth,...). Multiple antennas spatially distributed on the plastic casing become therefore a great challenge for cost and performances motivations, thus promoting flexible technology and substrate, for assembling sub-systems, under compactness considerations, as well as electrical performances improvement.

In this paper, we discuss about the characterisation of Multiband antennas designed on an ultra-low cost material (a cellulosic substrate, i.e. a paper) with design challenges in terms of radiation efficiency maximization and wideband properties under compactness constraints. Simulation and measurements are proposed to validate the designs.
\end{abstract}

Keywords - wideband antennas, Flexible Printed Circuit, paper substrates, conformable structure, integrated balun

\section{INTRODUCTION}

Antennas are usually processed on substrates external to the main PCB (Printed Circuit Board) of electronics devices. This is mainly due to the limited electrical properties (in terms of losses and high frequency operations) of conventionnal low cost PCBs usually considered as mechanical supporting structures only for digital sub-systems (processors, memories, basic electronics modules). Nevertheless, with the extensive use of multi-antennas wireless links, especially for internet of multimedia set-top-boxes which have to support simultaneously an increasing number of standards, specific constraints such as radiation efficiency (thus using low-loss cost effective thin substrates), spatial diversity for MIMO schemes (with up to $4 * 4$ colocated antennas per standards) are expected, leading to multiple input-output interconnections from the main PCB. In addition, antennas are usually processed on substrates external to the main PCB, so as to address specific constraints such as radiation efficiency (thus using low-loss cost effective thin substrates), spatial diversity for MIMO schemes (then requiring up to $4 * 4$ colocated antennas per standards and multiple interconnections towards external substrates preselected for their electrical performances at high frequencies, up to $6 \mathrm{GHz}$ ).
The flexibility is also required regarding geometrical implemenation of those different antennas, with spatial diversity for MIMO scheme performances, and drastic constraints in terms of decoupling and environment perturbations with surrounding elements of set-top boxes such as radiators and other metalized parts (display, batteries,..).

For such purpose, flexible substrates produce new opportunities and are widely used today to adress theses different integration and interconnection challenges. Nevertheles, cost has to be considered to remain compatible with well-controled low cost industrial process (for instance stamped metal antennas mechanically inserted in plastic casing).

The "Stick'It" project ("Printable passive antenna system in a conformable structure") aims to develop innovative low-cost technologies for the design of $2 \mathrm{D}$ and $2.5 \mathrm{D} R \mathrm{RF}$ interconnection components and sub-systems printed on flexible materials such as paper substrates and plastic films. The development of such substrates will make paper, in the near future, an excellent candidate for ultra-low-cost, flexible, and environmental friendly electronic systems.

We have tested different metallization methods and cellulosic based substrates for evaluating a new family of ultra-low cost interconnection substrates. In [1], we presented the design and characterisation of microstrip transmission lines screen-printed on a $240 \mu \mathrm{m}$ thick E4D paper substrate (experimental dielectric properties: $\varepsilon \mathrm{r}=2.54$ and $\tan \delta=0.05$ ), with a $7 \mu \mathrm{m}$ thick silver ink metallization. The next step consists here in the design of multi-frequency antennas (either multi-band or ultra-wide frequency band) on these flexible substrates (paper and PET). Antennas such as Vivaldi and monopole type are good candidates for wireless multimedia applications due to their wideband property.

In this work, we present different topologies of antennas processed on a E4D paper substrate, with multiband frequency performances covering the 2.4 and $5 \mathrm{GHz}$ Wifi frequencies. Part II describes a bi-band monopole antenna, with a double $\mathrm{C}$ configuration. An improved and original configuration of a wide band dipole is proposed in Part III. 


\section{DUAL-BAND MONOPOLE ANTENNA (2.4 GHz/5.5 GHz)}

We have developed monopole or dipole type antenna with multi-frequencies performances in order to satisfy the multistandard communication requirements of advanced multimedia set-up boxes.

The antenna must cover at least two frequency bands $2.4-2.5$ $\mathrm{GHz}$ and $5.15-5.85 \mathrm{GHz}$, with omnidirectional radiation pattern and minimum $60 \%$ radiation efficiency. Of course, manufacturing constraints are to be considered regarding the available fabrication technology. Most importantly, the antenna size is very limited to permit its integration into a settop-box by sticking it on plastic sidewalls of the casing. Specifically, the length of the radiator and ground should not exceed $3 \mathrm{~cm}$ (height of the electronic box).

Many solutions of planar dual-band monopole have been reported in the literature for wireless applications [2] [3]. All these antennas have two frequency bands which can be controlled independently. However, many of them have a quite large size not compatible with the required compactness feature. Therefore, we have chosen a folded monopole, inspired from Jyoti et al, 2011 [2] to implement a dual-band monopole structure. The expected bandwidths for WLAN applications can be reached, considering also miniaturization criterias (use of meandered lines) with simple geometry. The main drawback is probably its non-ideal monopole-like radiation pattern at $5.5 \mathrm{GHz}$ due to the influence of the long $\mathrm{C}$ branch.

\section{1) Dual frequency behaviour}

This dual-band Wi-Fi monopole has been designed by parametric optimization for WLAN applications at $2.4-2.5$ $\mathrm{GHz}$ and $5.15-5.85 \mathrm{GHz}$. The layout and the prototype of this antenna screen-printed on E4D-100 $\mu \mathrm{m}$ paper are shown on figure 1 .

This monopole, with a compact size $\left(17.5 \times 12 \mathrm{~mm}^{2}\right)$, exhibits two resonance frequencies and two associated bandwidths that can be controlled independently.

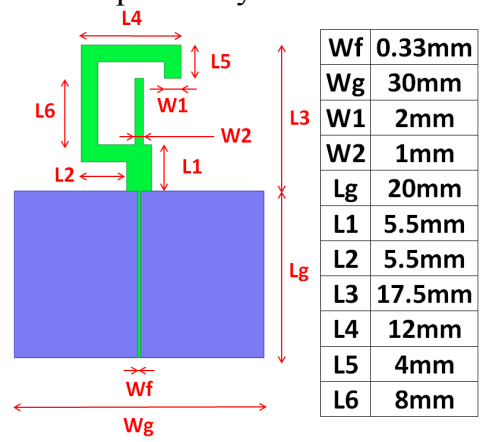

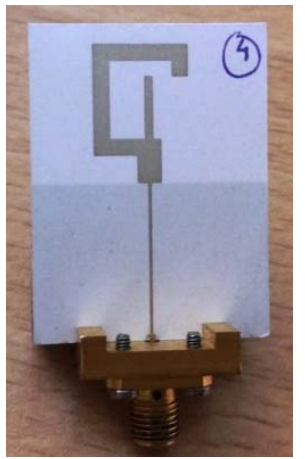

Fig. 1. Layout and prototype of the dual-band Wi-Fi monopole antenna, screen-printed on E4D-100 $\mu$ m paper

It has two radiating elements: a hook-shaped branch for the low frequency band and a straight branch for high frequencies. Its structure is also simple, appropriate for the double-sided printing process on paper substrate, and there are no special technical requirements for antenna fabrication (no via holes realization, for example).

The behavior of the antenna has been studied through the visualization of current distributions using HFSS EMsimulations in order to verify the independence of the two frequency bands (2.4 and $5.5 \mathrm{GHz}$ - see figure 2). It can be seen that the hook-shape branch has a high current density and appears to be "active" at $2.4 \mathrm{GHz}$ (see figure $2 a$ ). On the other hand, the straight branch is more "active" at $5.5 \mathrm{GHz}$. It can be seen that the current is concentrated mostly around the straight branch (see figure $2 b$ ).

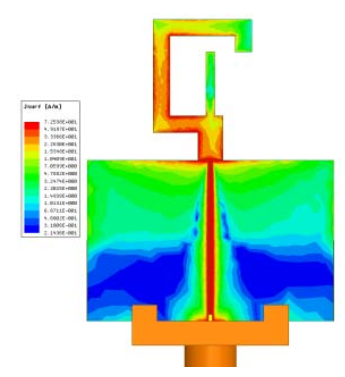

(a)

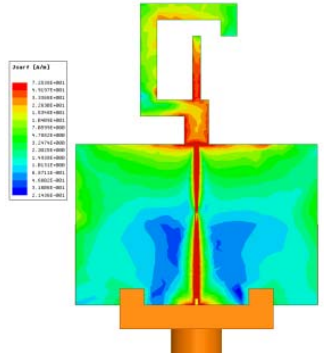

(b)
Fig. 2. Simulated current distribution at: (a) $2.4 \mathrm{GHz}$ and (b) $5.5 \mathrm{GHz}$.

\section{2) Parametric study}

The two branches appear as quite independent in terms of electrical behavior in the two sub-bands. Thus, a parametric analysis has been carried out by varying one of the effective length parameters while keeping constant the other length parameters of the antenna to reach the optimized dimensions, as illustrated in figure $6 a \& b$. 


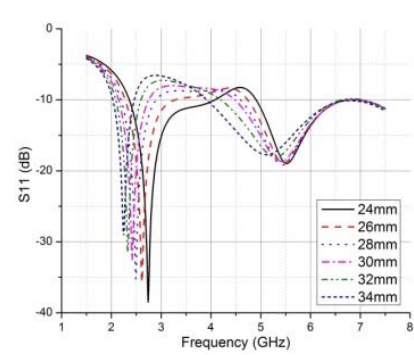

a)

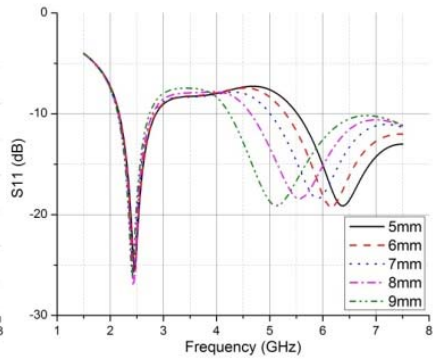

b)
Fig. 3. Effects of changing L3 and L6 on the $2.4 \mathrm{GHz}$ and $5.5 \mathrm{Ghz}$ frequencies

The resonance frequencies, as well as the associated bandwidths of the antenna, are sensitive to the length of each branch. Hence, the performance of this antenna could be sensitive to the fabrication process tolerances. However, considering the printing technology accuracy (about \pm 0.05 $\mathrm{mm}$ ), a negligible impact has been observed.

The return loss $\mathrm{S}_{11}$, radiation patterns and gains of this antenna at $2.4 \mathrm{GHz}$ and $5.5 \mathrm{GHz}$ were measured to be compared with the EM simulations. A small metallic support $\left(10 \times 30 \times 10 \mathrm{~mm}^{3}\right)$ was used to attach the SMA connector to the antenna for measurements.

A reasonably good concordance was obtained between the measurement and the simulated $\mathrm{S}_{11}$ parameter. Obviously, the agreement is improved when the connector and the attached cable is considered. The simulated, respectively measured return loss, are displayed in figure 4, yielding a 1st frequency at $2.4 \mathrm{GHz}(0.64 \mathrm{GHz}$ bandwidth, respectively $0.44 \mathrm{GHz}$ @TOS=2) and a 2nd frequency at $5.5 \mathrm{GHz}(2.22 \mathrm{GHz}$ bandwidth, respectively 1.55GHz@TOS=2).

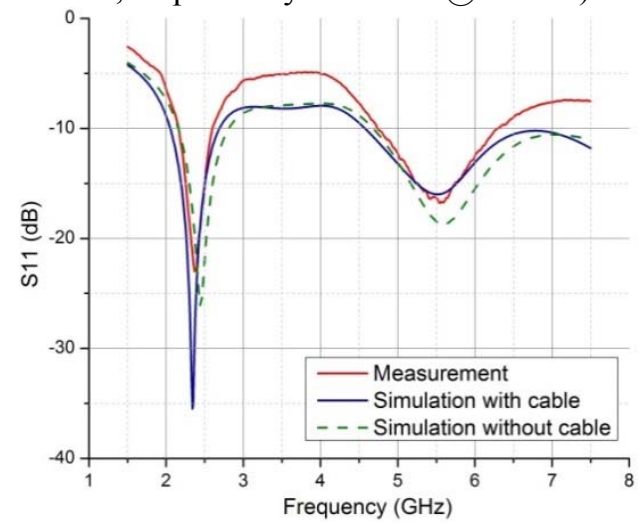

Fig. 4 Return loss $\mathrm{S}_{11}$ of this dual-band Wi-Fi monopole antenna

\section{3) Radiation patterns measurement}

The radiation patterns measured at $2.4 \mathrm{GHz}$ and $5.5 \mathrm{GHz}$ with a MVG Stargate ${ }^{\circledR}$ system (SG-24) show a good agreement with the HFSS simulations (cf. figure 5). It can be observed that the H-plane radiation patterns are almost omnidirectional at both resonant frequencies. At $2.4 \mathrm{GHz}$, the simulated and measured results exhibit a bi-directional monopole-shape radiation pattern in the E-plane. The E-plane graph is slightly tilted and distorted due to the influence of the attached connector with the metallic support. At $5.5 \mathrm{GHz}$, we have no longer a bi-directional monopole behavior in the E-plane due to the influence of the hook-shaped branch into the radiation pattern of the straight branch.

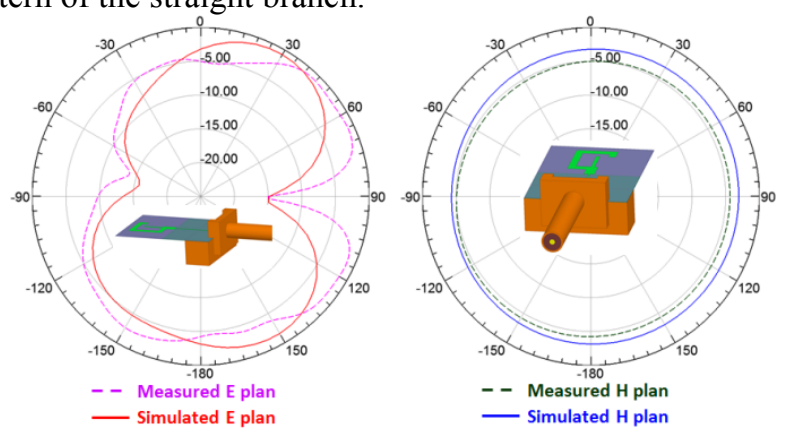

(a)

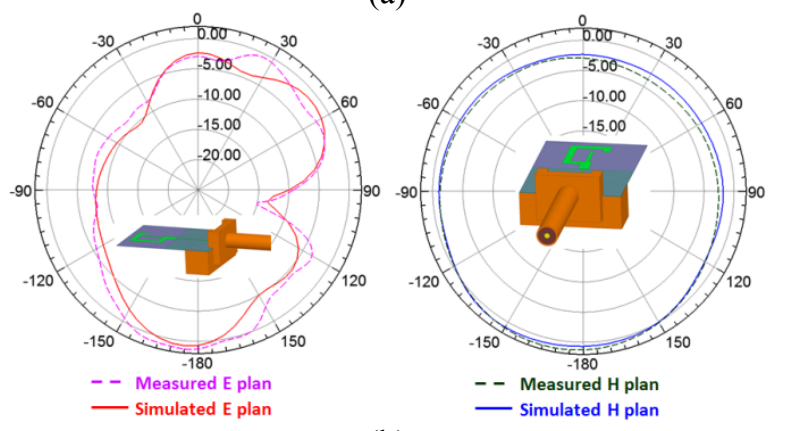

(b)

Fig. 5 E-Plane and H-Plane radiation patterns of dual-band Wi-Fi monopole antenna at: (a) $2.4 \mathrm{GHz}$ and (b) $5.5 \mathrm{GHz}$

The simulated and measured max realized gains versus frequency (figure 6 ) are also fairly consistent: $1.42 \mathrm{dBi}$ and $1.87 \mathrm{dBi}$ at $2.4 \mathrm{GHz}, 3.21 \mathrm{dBi}$ and $4.1 \mathrm{dBi}$ at $5.5 \mathrm{GHz}$, respectively (excluding insertion losses in the $20 \mathrm{~mm}$ feed line: $2.1 \mathrm{~dB}$ at $2.4 \mathrm{GHz}$ and $3.1 \mathrm{~dB}$ at $5.5 \mathrm{GHz}$ ).

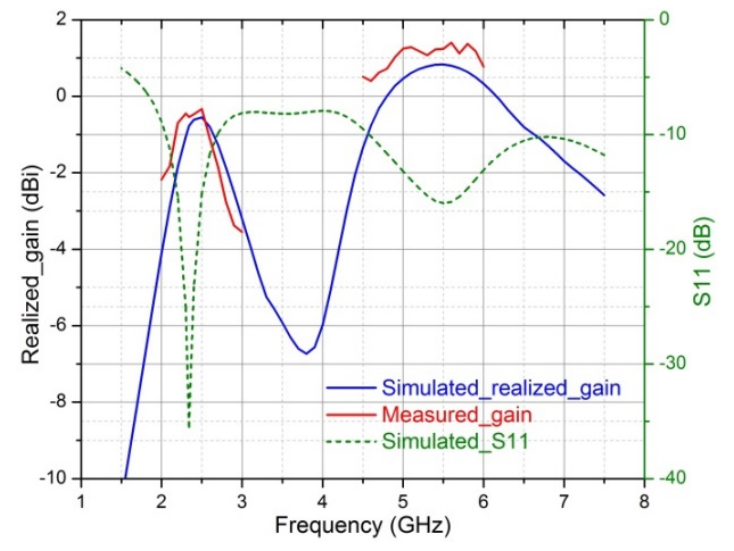

Fig. 6 Simulated and measured realized gain of the antenna versus frequency

\section{Planar DUAL-BAND DiPOLE ANTENNA (2.4 GHz/5.5 GHz)}

Dipole antennas usually exhibit a wider impedance bandwidth than monopoles. We consequently investigate a dual-band 
dipole prototype that is intended to be stuck on the sidewall of a set-top-box for WLAN applications $(2.4 \mathrm{GHz}$ and $5.5 \mathrm{GHz})$. We have developed a new model of broadband dipole antenna, which was screen-printed on E4D-210 $\mu \mathrm{m}$ paper. The form factor was optimized, as depicted in figure 7 , to extend the bandwidth while reducing the overall size. Considering such wideband dipole antenna, the innovation lies also on the implicit integration of the balun.
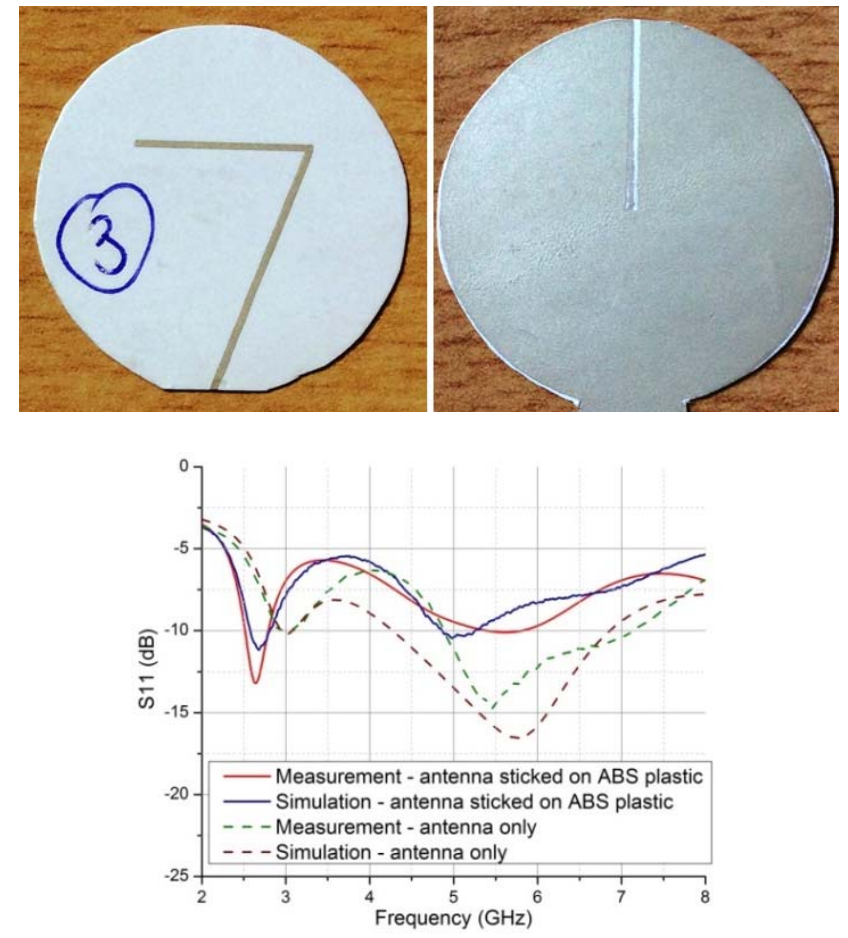

Figure 7: Prototype and return loss of a modified ultra-wideband dipole

The structure was then adjusted to improve the impedance matching and to add a second sub-band for the dual-band $\mathrm{Wi}$ Fi dipole antenna. Two slots are inserted to modify the current distribution and generate a second resonance at $5.5 \mathrm{GHz}$. The second dipole is inserted into the first one to create two dipole antennas (one operates at $2.45 \mathrm{GHz}$ and the other at $5.5 \mathrm{GHz}$ ) on the same radiation structure, as presented in figure 8 . The circular ground plane was also truncated to reduce the overall size of the antenna and to decrease the length of feeding line to $21 \mathrm{~mm}$ (so, reducing the insertion losses in the feed line) [4].

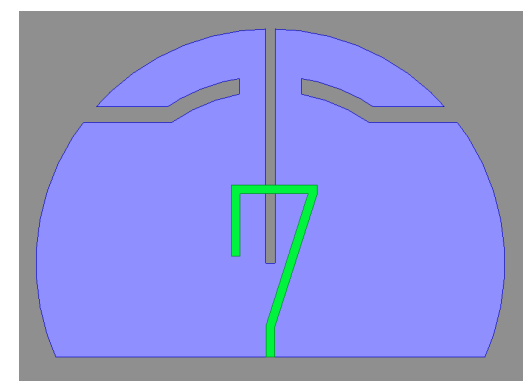

Fig. 8 New Prototype of the dual-band Wi-Fi dipole antenna, screen-printed on $\mathrm{E} 4 \mathrm{D}-200 \mu \mathrm{m}$ paper
This dual-band Wi-Fi dipole exhibit two bandwidths@ [2.4 - $2.63 \mathrm{GHz}](9.2 \% @ \mathrm{ROS}=2)$ and $[4.59$ - $6.43 \mathrm{GHz}]$ (36.1\%). A fairly good agreement was obtained between the measurement and the HFSS simulation of $\mathrm{S}_{11}$

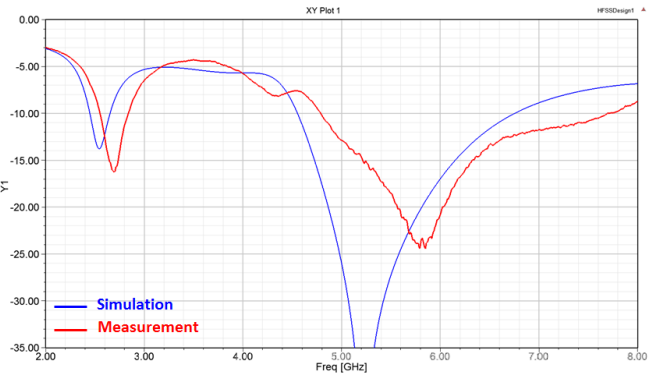

Fig. 8 - S11 measured and simulated dual-band Wi-Fi dipole antenna

The simulated max realized gain of this dipole is $-0.23 \mathrm{dBi}$ at $2.5 \mathrm{GHz}$ and $3.3 \mathrm{dBi}$ at $5.5 \mathrm{GHz}$, respectively. The simulated total efficiency was $54.8 \%$ at $2.5 \mathrm{GHz}$ and $92.2 \%$ at $5.5 \mathrm{GHz}$, respectively (excluding losses in the $21 \mathrm{~mm}$ feed line). The planar dual-band dipole shows also a good performance in terms of radiation pattern, gain and efficiency and appears as a good solution for the final antenna system

\section{CONCLUSION}

During the conference, we will present the complete experimental and simulation results concerning both transmission lines and antennas performed on paper substrates. The simulations are almost in good agreement with the measurement results. Antennas printed on paper operates up to at least $6 \mathrm{GHz}$. The next issue of the work will concern a final demonstrator using spatially distributed antennas for radiation patterns and consequently special diversity and multistandards capabilities.

\section{ACKNOWLEDGMENT}

The authors would like to acknowledge the support of Agence Nationale de la Recherche for financial support under grant ANR-IG-CE26-0033-01.

\section{REFERENCES}

[1] H. D. Nguyen et al, "RF characterization of flexible substrates for new conformable antenna systems", 10th European Conference on Antennas and Propagation, 2016.

[2] J. R. Panda et al, "A compact printed monopole antenna for dual-band RFID and WLAN applications", Radioengineering n²0, p.464-467, June 2011

[3] Yuan Zhu et al, "A compact dual-band monopole antenna for 4G LTE and WIFI utilizations," 2016 IEEE MTT-S International Microwave Workshop (IMWS-AMP), Chengdu, 2016, pp. 1-4.

[4] J.Ph. Coupez et al. "Dual Fin antenna" US2012/0112967 patent application 2012 